\title{
Left Ventricular Dyssynchrony in Acute ST Elevated Myocardial Infarction in Patients with Normal QRS duration
}

Iftekhar Alam¹, Tuhin Haque ${ }^{2}$, Mohammad Badiuzzaman³ ${ }^{3}$ Abdullah Al Masud ${ }^{4}$, Abrar Kaiser ${ }^{5}$, Md. Moniruzzaman ${ }^{6}$

\begin{abstract}
:
Background: The aim of this study was to assess left ventricular dyssynchrony after acute ST elevated myocardial infarction (STEMI) in patients with normal QRS duration. Real time 3D echocardiography (RT3DE) with triplane tissue synchronization imaging (TSI) used to identify segmental left ventricular systolic velocity in ejection phase to evaluate LV dyssynchrony in patients with STEMI and the findings were compared with control.

Materials and methods: RT3DE with triplane TSI was performed within 4 days of AMI after thrombolysis or primary $\mathrm{PCl}$ in 31 patients and compared with 31 agematched controls. Regional myocardial velocities were assessed in 12 segments in ejection phase, and the corresponding time to peak systolic velocity (Ts) was measured. To assess LV dyssynchrony Ts-4, Ts-6, TsSD-6, Ts-12 and Ts-SD-12 were computed by offline dedicated software semi-automatically.
\end{abstract}

Results: The dyssynchrony parameters were significantly prolonged in patients with AMI. Among the dyssynchrony parameters TS-SD-12 was better indicator of LV dyssynchrony. The Ts-SD-12 was significantly prolonged in the STEMI group when compared with controls. In patients with acute STEMI mean Ts-SD-12 was $43.2 \pm 19.1$ milliseconds whereas in control group it was $23.0 \pm 6.5$ milliseconds $(p<0.05)$. The Ts-SD-12 was prolonged in patients with Anterior than Inferior STEMI as follows respectively $45.9 \pm 17.6$ and $40.0 \pm$ 21 milliseconds.

Conclusions: Triplane TSI by RT3DE is useful in evaluating LV dyssynchrony in patients with acute STEMI and even in those with normal QRS duration there is significant left ventricular dyssynchrony early after STEMI.

Key words: STEMI, LV dyssynchrony, RT3DE, time to peak systolic velocity in ejection phase (TS).

(Bangladesh Heart Journal 2015; 30(1) : 13-21)

Introduction:

In normal heart, the left ventricle (LV) contracts and relaxes in a synchronous manner. Dyssynchrony refers to the uncoordinated mechanical contraction of the heart. Systolic dyssynchrony can be defined as uncoordinated timing of contraction in different segments of the myocardium. ${ }^{1}$ Conventionally dyssynchrony is related with

1. Registrar, National Institute of Cardiovascular Diseases, Shere Bangla Nagar, Dhaka. E-mail: iftekhar1029@gmail.com

2. Professor of Echocardiography, National Heart Foundation Hospital \& Research Institute (NHF\&RI), Mirpur, Dhaka.

3. Professor of Cardiology, National Heart Foundation Hospital \&Research Institute, Mirpur, Dhaka.

4. Assistant Registrar, National Institute of Cardiovascular Diseases, Shere Bangla Nagar, Dhaka.

5. Junior Consultant(Cardiology), BGB Hospital, Pilkhana, Dhaka.

6. Assistant Prof. of Cardiology, Khwaja Younus Ali Medical College and Hospital, Sirajgonj. heart failure, cardiomyopathy, conduction defect and bundle branch block and is used as predictor of cardiac resynchronisation therapy (CRT) response. But recently LV dyssynchrony is assessed in patients with AMI as a predictor of LV remodeling and is a non-invasive indirect procedure for detection of infarct size. ${ }^{2}$ Dyssynchrony early after AMI causes severe LV dysfunction as a consequence of early cardiac remodeling, elevation of filling pressure, reduced diastolic filling, reduced LV stroke volume and reduced CO. ${ }^{3}$

Acute myocardial infarction causes remodeling of LV due to complex alterations in ventricular architecture involving both infarcted and noninfarcted zones. ${ }^{4}$ Left ventricular remodeling develops in considerable proportion of patients after AMI despite successful treatment with thrombolysis and primary $\mathrm{PCl}$ and even in the presence 
of patent infarct related artery and associated with increased cardiovascular events and mortality. ${ }^{5}$ Therefore, early identification of patients at risk for developing LV remodeling after AMI has important prognostic and therapeutic implications. In addition, it was demonstrated that dyssynchrony associated with AMI was mainly determined by the infarct size. ${ }^{6}$

Advances in echocardiographic techniques, i.e. tissue Doppler echocardiography, speckle-tracking echocardiography, and real-time 3-dimensional echocardiography have demonstrated an impaired left ventricular synchronicity in patients with acute myocardial infarction. ${ }^{7}$ Myocardial Tissue Doppler Imaging (TDI) is an ultrasound technique that provides assessment of the contracting myocardium by measuring myocardial velocities. $^{8}$

Among the echocardiographic tools used to evaluate mechanical dyssynchrony, TDI analysis occupies a prominent position and the use of colour-coded TDI for dyssynchrony assessment is presently advocated. ${ }^{9}$ The major advantage of colour-coded TDI is the simultaneous comparison of various LV segments. Tissue Synchronization Imaging (TSI) can be used to assess intra-ventricular dyssynchrony in the longitudinal plane (apical views).Using a triplane imaging probe (3D probe) from the apical window, simultaneous grey-scale images can be acquired in apical four, two and three chamber views. Simply by activating colour-coded TDI during the triplane acquisition, information on the myocardial velocities of various LV segments in these three planes can be obtained during the same heartbeat. TSI can also be applied to a triplane dataset. The TSI tool will automatically calculate the time to peak myocardial systolic velocities in several LV segments and generate a report and a colour scheme with the different activation times of those LV segments. ${ }^{10}$

RT3DE provides optimal information of LV volumes, functions and sphericity. ${ }^{11}$ Although role of LV dyssynchrony as a predictor of remodeling after AMI is well established but its relation with traditional echocardiographic prognostic parameter of LV function and other variables remain imprecise. So this study was designed to compare the dyssynchrony parameters between case and control groups and to assess correlation with LV volumes and functions.

\section{Materials and methods:}

This case control study was done during the period of June 2012 to May 2013 at National Heart Foundation Hospital \& Research Institute (NHF\&RI). In group I, 31 patients with Acute STEMI with normal QRS duration admitted in CCU of NHF\&RI treated either by thrombolysis or primary $\mathrm{PCl}$ were included and 31 agematched healthy controls were enrolled in group II. Samples were collected on the basis of inclusion and exclusion criteria without any randomization. Patients with previous MI, wide QRS complex (>120ms), heart failure, history of previous PTCA or CABG, Pacemaker, CRT or ICD implantation and with poor echo window with inadequate Doppler signal and suboptimal two dimensional images were excluded.

Meticulous history was taken and detailed clinical examination performed in both groups. Demographic data and risk factors were recorded, 12 lead ECG and blood biochemistry done. Echocardiography was done within four day of acute STEMI.

\section{Echocardiography:}

Comprehensive echocardiography was performed in each patient with standard echocardiography machine Vivid E9 (Vingmed- General Electric, Horten, Norway).

\section{D M-mode}

All case and controls were imaged in the left lateral decubitus position. Standard images were obtained using a $3.5-\mathrm{MHz}$ transducer, at a depth of $16 \mathrm{~cm}$ in the parasternal long axis (PLAX) and short-axis (SAX); apical four chamber (A4C), apical two chamber (A2C) and apical long axis (ALAX) views. The LV was divided into 17 segments including true apex for quantifying wall motion score index (WMSI). A semi-quantitative scoring system e.g. 1-normal, 2-hypokinesia, 3-akinesia and 4dyskinesia was used to analyze both case and control groups. Global WMSI was calculated by the standard formula: sum of the segment score divided by number of segment scored. ${ }^{12}$

\section{Real time 3 Dimensional Echocardiography (RT3DE)}

RT3DE allows intra-ventricular volumes and dyssynchrony to be evaluated by analyzing LV wall motion in multiple apical planes during the same cardiac cycle and provide better spatial resolution than a single plane.

RT3DE was performed at the same time to assess global LV systolic function and LV dyssynchrony with 3D phased array transducer $(2.5 \mathrm{MHz})$. Apical full volume 3D data sets were acquired in harmonic mode, integrating during a brief breath-hold (3-4 Seconds), R wavetriggered sub-volumes into a larger pyramidal volume $\left(90^{\circ}\right.$ by $\left.90^{\circ}\right)$ with a complete capture of the LV. ${ }^{13}$ Dedicated algorithm was used by specific software to calculate LV end-diastolic volume (EDV), LV end-systolic volume (ESV) 
and left ventricular ejection fraction (LVEF). A semiautomated method by software Echopac BT12, GE Vingmed Ultrasound for the detection of the apical 4chamber view and the $60^{\circ}$ and $120^{\circ}$ incremental views and for the tracing of the endocardial border in the entire 3D dataset including LV trabeculations and papillary muscles within the LV volume was used. Subsequently, a final reconstruction of the LV model was generated and LV volumes and LVEF were obtained. This software also enables tissue tracking by colour coding the displacement in the myocardium and allowed quantitative analysis of multiple tissue velocity traces. ${ }^{14}$

To measure the time to peak systolic velocity in the ejection phase (TS) by RT3DE based TSI of individual segments, the following rules were used:

- Aortic valve opening and closure was marked and superimposed on TDI tracings to guide the identification of the ejection phase.

- Time was measured from the onset of the QRS complex to the highest systolic peak during the ejection phase (between aortic valve opening and closure).

- If there were multiple peaks in the ejection phase, the highest peak was used.

- If the segment had only a negative peak in the ejection phase or the velocity was noisy with very low and inconsistent velocities, those particular segments were neglected, and

- Ts were not measured on the isovolumic contraction phase or isovolumic relaxation phase or during postsystolic shortening. ${ }^{1}$

The RT3DE approach acquires three standard apical views during the same heart beating (triplane). The images were acquired in TSI modality, thus allowing 3-D "surface rendering" visualization of the extent of dyssynchrony. The method is fast (a few seconds) and easy to perform. ${ }^{15}$ During acquiring an apical $4 \mathrm{C}$ view, the multi-dimension button was pressed followed by the tri-plane button. A full sector of the desired imaging plane was acquired for simultaneous visualization and to compare all the walls within the left ventricle. Accurate TSI analysis achieved with frame rates around100fps or higher. TVI was acquired by entering TVI mode. Optimize 2D gain required for a clean chamber that is free of noise by simply depressing the gain button and ECG trace, free of noise and with a consistent heart rate was used and image was acquired in cine loop. Then TSI mode selected and the image was colorized according to the time-to positive peak systolic velocity. Regions reaching peak velocity early in systole were marked in green. Regions reaching peak velocity late in systole or in diastole were marked yellowish to red. The loop was freezed in a late diastolic frame and a tri-plane TSI image displayed. For measurement TSI myocardium surface selected by tracking curser at basal and mid LV in 4 opposing segments of myocardium starting on the left side of the $A 4 C$ view and ending on right side. Process automatically selects segments on A2C and ALAX views of triplane image. TSI software automatically calculates the time to peak myocardial systolic velocities in $12 \mathrm{LV}$ segments and generate a report and a colour scheme with the different activation times of these LV segments. The colour schemes can be projected on a surface rendered endocardial volume and a bulls-eye view TSI report which was automatically generated with parameters of LV dyssynchrony. ${ }^{16}$

For detection of LV dyssynchrony the following parameters with cut off values were used: 17

- Opposing segment delay (Ts-4) >60 ms

- Maximal difference in Ts between any of the 6 basal LV segments (Ts-6) $>110 \mathrm{~ms}$

- Standard deviation of Ts of the 6 basal LV segments (Ts-SD-6) >34.5 ms

- Maximal difference in Ts of the 12 LV segments (Ts12) $>100 \mathrm{~ms}$

- Standard deviation of Ts of the 12 LV segments (TsSD-12) $>34.4 \mathrm{~ms}$

\section{Statistical Methods:}

The collected data were checked and coded manually and then entered into a computer database. All analyses were performed using the SPSS (SPSS for Windows 17.0) software package. Continuous variables were presented as mean \pm standard deviation. Categorical variables were presented as the percentage. Chi-square test, Fisher exact test and continuity correction were used for categorical variables and unpaired t-test was used for continuous variables if appropriate. Pearson's and Spearmen correlation exponents were used to force of relationship between continuous variables. A value of $p<$ 0.05 was considered statistically significant.

\section{Results:}

The mean age of group I patients was $48.6 \pm 11.6$ years and $45.6 \pm 10.4$ years for group II patients (Table I). The commonest age group of study patients was $41-50$ years in both the groups (29\% and $30 \%$ in group I and group 
II respectively). Male patients were predominant in both groups; there were 6.5 percent female in group I and 6.7 percent female in group II. Smoking, hypertension, obesity and dyslipidaemia were the most common risk factors in both groups. Family history of IHD and diabetes were significant risk factors in group I (Table II). In 87.1\% ( $\mathrm{n}=27$ ) patients in Group I was treated by thrombolysis with Streptokinase and $12.9 \%(n=4)$ by Primary $\mathrm{PCl}$.

Table-I

Age distribution of the study population $(n=62)$

\begin{tabular}{lcccccc}
\hline $\begin{array}{l}\text { Age } \\
\text { (years) }\end{array}$ & \multicolumn{2}{c}{$\begin{array}{c}\text { Group I } \\
\text { (Case: } n=31)\end{array}$} & & \multicolumn{2}{c}{$\begin{array}{c}\text { Group II } \\
\text { (control: } n=31)\end{array}$} & P value \\
\cline { 2 - 3 } \cline { 5 - 6 } & Number & $\%$ & & Number & $\%$ & \\
\hline$<30$ & 2 & 6.5 & 3 & 10.0 & \\
$31-40$ & 7 & 22.6 & 7 & 23.3 & \\
$41-50$ & 9 & 29.0 & & 10 & 30.0 & \\
$51-60$ & 8 & 25.8 & & 26.7 & \\
$>60$ & 5 & 16.1 & & 3 & 10.0 & \\
Mean $\pm S D$ & $48.6 \pm 11.6$ & & $45.6 \pm 10.4$ & $0.286^{N S}$ \\
\hline
\end{tabular}

Table-II

Risk factors of the study population $(n=62)$

\begin{tabular}{lcccccc}
\hline $\begin{array}{l}\text { Risk } \\
\text { factor }\end{array}$ & \multicolumn{2}{c}{$\begin{array}{c}\text { Group I } \\
(\mathrm{n}=31)\end{array}$} & & \multicolumn{2}{c}{$\begin{array}{c}\text { Group II } \\
(\mathrm{n}=31)\end{array}$} & $\mathrm{P}$ value \\
\cline { 2 - 3 } \cline { 5 - 6 } & Number & $\%$ & & Number & $\%$ & \\
\hline Smoking & 17 & 54.8 & & 16 & 53.3 & $0.309^{\mathrm{NS}}$ \\
Hypertension & 20 & 64.5 & & 19 & 63.3 & $0.923^{\mathrm{NS}}$ \\
Dyslipidaemia & 22 & 71.0 & & 17 & 56.7 & $0.245^{\mathrm{NS}}$ \\
Family H/O IHD & 16 & 51.6 & & 9 & 30.0 & $0.021^{\mathrm{S}}$ \\
Diabetes & 14 & 45.2 & & 7 & 23.3 & $0.034^{\mathrm{S}}$ \\
$\begin{array}{l}\text { Obese \& over } \\
\text { weight }\end{array}$ & 14 & 45.1 & & 16 & 53.2 & $0.644^{\mathrm{NS}}$ \\
\hline
\end{tabular}

Among the patients with myocardial infarction 17 (54.8\%) suffered from AMI anterior and 14(45.2\%) from AMI inferior. Baseline investigation revels significantly high cardiac markers (table III).

Table-III

Baseline clinical examination and investigation findings of study population $(n=62)$

\begin{tabular}{lccc}
\hline Variables & $\begin{array}{c}\text { Group I }(\mathrm{n}=31) \\
\text { Mean } \pm \mathrm{SD}\end{array}$ & $\begin{array}{c}\text { Group II }(\mathrm{n}=31) \\
\text { Mean } \pm \mathrm{SD}\end{array}$ & $\mathrm{P}$ value \\
\hline Heart rate & $72.2 \pm 12.3$ & $71.2 \pm 10.4$ & $0.836^{\mathrm{NS}}$ \\
Systolic BP & $117.4 \pm 18.9$ & $125.6 \pm 14.5$ & $0.093^{\mathrm{NS}}$ \\
Diastolic BP & $75.8 \pm 9.1$ & $79.1 \pm 7.9$ & $0.418^{\mathrm{NS}}$ \\
BMI & $25.0 \pm 2.3$ & $25.2 \pm 3.8$ & $0.220^{\mathrm{NS}}$ \\
QRS duration & $93.6 \pm 11.9$ & $84.3 \pm 6.3$ & $0.001^{\mathrm{S}}$ \\
RBS $(\mathrm{mg} / \mathrm{dl})$ & $8.8 \pm 3.8$ & $5.6 \pm 0.7$ & $0.0001^{\mathrm{S}}$ \\
Serum Creatinine $(\mathrm{mg} / \mathrm{dl})$ & $1.2 \pm 0.24$ & $1.0 \pm 0.09$ & $0.001^{\mathrm{S}}$ \\
CK MB $(\mathrm{u} / \mathrm{L})$ & $227.3 \pm 125.6$ & $28.4 \pm 8.2$ & $0.0001^{\mathrm{S}}$ \\
Serum Troponin I(ng/ml) & $43.9 \pm 8.2$ & $0.0 \pm 0.0$ & $0.0001^{\mathrm{S}}$ \\
Total Cholesterol(mg/dl) & $200.7 \pm 46.5$ & $201.8 \pm 36.2$ & $0.920^{\mathrm{NS}}$ \\
HDL $(\mathrm{mg} / \mathrm{dl})$ & $39.7 \pm 9.1$ & $39.4 \pm 4.6$ & $0.071^{\mathrm{NS}}$ \\
LDL(mg/dl) & $129.4 \pm 36.1$ & $147.6 \pm 12.7$ & $0.086^{\mathrm{NS}}$ \\
Triglycerides $(\mathrm{mg} / \mathrm{dl})$ & $164.0 \pm 54.8$ & $199.0 \pm 36.4$ & $0.057^{\mathrm{NS}}$ \\
\hline
\end{tabular}

The patients with STEMI had reduced ejection fraction, increased wall motion score index, greater left ventricular volumes evident by measurement of RT3DE end diastolic and end systolic volumes than the control group (Table IV). End systolic volume and WMSI index was significantly higher in anterior MI than inferior MI (Table-V).

Table-IV

Distribution of the groups by RT3DE parameters $(n=62)$

\begin{tabular}{lccl}
\hline RT3DE & $\begin{array}{c}\text { Group I }(\mathrm{n}=31) \\
\text { Mean } \pm \text { SD }\end{array}$ & $\begin{array}{c}\text { Group II }(\mathrm{n}=31) \\
\text { Mean } \pm \text { SD }\end{array}$ & P value \\
\hline EDV $\left(\mathrm{ml} / \mathrm{m}^{2}\right)$ & $87.0 \pm 16.2$ & $78.2 \pm 13.6$ & $0.542^{\mathrm{NS}}$ \\
$\operatorname{ESV}\left(\mathrm{ml} / \mathrm{m}^{2}\right)$ & $47.5 \pm 13.2$ & $31.2 \pm 5.2$ & $0.001^{\mathrm{s}}$ \\
EF $(\%)$ & $45.2 \pm 6.2$ & $60.1 \pm 1.4$ & $0.0001^{\mathrm{s}}$ \\
WMSI & $1.5 \pm 0.25$ & $1.0 \pm 0.0$ & $0.0001^{\mathrm{s}}$ \\
\hline
\end{tabular}

In the normal controls RT3D echocardiography derived TSI results revealed, there was no significant variance in time to peak myocardial systolic velocity (Ts) among LV segments. However, Ts of the patients with STEMI in group I was significantly prolonged when compared with controls in group II (Table- VI). in contrast, in patients with anterior MI Ts-12 and Ts-Sd-12 parameters were high and in inferior MI Ts-4, Ts-6, Ts-SD-6 were higher (Table - VII). LV dyssynchrony was identified in 54.8\% $(\mathrm{n}=17)$ by $\mathrm{Ts}=\mathrm{SD}-12$ in Group I and was better than other parameters (Table-VIII).

Table-V

Distribution of the patients in group I by RT3DE parameters $(n=31)$

\begin{tabular}{lccc}
\hline RT3DE & $\begin{array}{c}\text { AMI Anterior AMI } \\
(\mathrm{n}=17) \\
\text { Mean } \pm \text { SD }\end{array}$ & $\begin{array}{c}\text { Inferior } \\
(\mathrm{n}=14) \\
\text { Mean } \pm \mathrm{SD}\end{array}$ & P value \\
\hline $\mathrm{EDV}\left(\mathrm{ml} / \mathrm{m}^{2}\right)$ & $91.0 \pm 19.1$ & $82.2 \pm 10.7$ & $0.123^{\mathrm{NS}}$ \\
$\mathrm{ESV}\left(\mathrm{ml} / \mathrm{m}^{2}\right)$ & $52.6 \pm 14.5$ & $41.3 \pm 8.4$ & $0.012^{\mathrm{S}}$ \\
$\mathrm{EF}(\%)$ & $42.7 \pm 6.2$ & $48.4 \pm 4.8$ & $0.08^{\mathrm{NS}}$ \\
WMSI & $1.6 \pm 0.3$ & $1.3 \pm 0.1$ & $0.011^{\mathrm{S}}$ \\
\hline
\end{tabular}

There was significant positive correlation between TsSD-12 and WMSI (Pearson correlation -.478, p (2 - 0.007) but correlation with EDV, ESV and EF was not significant although both these values were significantly higher in patients with STEMI (Figure-3). 
Table-VI

Distribution of the groups by RT3DE time to peak systolic velocity in ejection phase parameters $(n=62)$

\begin{tabular}{lccc}
\hline Time to peak systolic velocity in ejection phase (Ts) & $\begin{array}{c}\text { Group I }(\mathrm{n}=31) \\
\text { Mean } \pm \mathrm{SD}\end{array}$ & $\begin{array}{c}\text { Group II }(\mathrm{n}=31) \\
\text { Mean } \pm \mathrm{SD}\end{array}$ & P value \\
\hline Ts-4 (Opposing segment delay) & $55.8 \pm 47.4$ & $23.2 \pm 18.8$ & $0.001^{\mathrm{S}^{*}}$ \\
Ts-6 (Maximum difference of TS- 6 basal segments) & $73.1 \pm 54.1$ & $45.1 \pm 25.3$ & $0.003^{\mathrm{S}^{*}}$ \\
Ts-SD-6(Standard deviation of Ts of 6 basal segments) & $36.2 \pm 19.5$ & $21.4 \pm 8.1$ & $0.0001^{\mathrm{S}^{*}}$ \\
Ts-12 (Maximum difference of Ts-12 LV segments) & $132.8 \pm 51.9$ & $70.9 \pm 24.5$ & $0.001^{\mathrm{S}^{*}}$ \\
Ts-SD-12(Standard deviation of Ts- 12 LV segments) & $43.2 \pm 19.1$ & $23.0 \pm 6.5$ & $0.0001^{\mathrm{S}^{*}}$ \\
\hline
\end{tabular}

Table-VII

Distribution of the group I patients by RT3DE time to peak systolic velocity in ejection phase $(n=31)$

\begin{tabular}{|c|c|c|c|}
\hline Time to peak systolic velocity in ejection phase (Ts) & $\begin{array}{c}\text { AMI Anterior }(\mathrm{n}=17) \\
\text { Mean } \pm \mathrm{SD}\end{array}$ & $\begin{array}{c}\text { AMI Inferior }(n=14) \\
\text { Mean } \pm S D\end{array}$ & $P$ value \\
\hline Ts-4 (Opposing segment delay) & $48.1 \pm 32.0$ & $65.2 \pm 61.2$ & $0.356^{\mathrm{NS} *}$ \\
\hline Ts-6 (Maximum difference of TS- 6 basal segments) & $56.5 \pm 39.2$ & $64.2 \pm 41.2$ & $0.292^{\mathrm{NS} *}$ \\
\hline Ts-SD-6(Standard deviation of Ts of 6 basal segments) & $35.4 \pm 15.3$ & $37.3 \pm 24.3$ & $0.798^{\mathrm{NS}}{ }^{*}$ \\
\hline Ts-12 (Maximum difference of Ts-12 LV segments) & $140.2 \pm 52.3$ & $124.0 \pm 51.8$ & $0.397^{\mathrm{NS}^{*}}$ \\
\hline Ts-SD-12 (Standard deviation of Ts- 12 LV segments) & $45.9 \pm 17.6$ & $40.0 \pm 21.0$ & $0.414^{\mathrm{NS}}{ }^{*}$ \\
\hline
\end{tabular}

Table-VIII

Distribution of LV Dyssynchrony in group I by time to peak systolic velocity in ejection phase $-T s$. (n=31)

\begin{tabular}{lcccc}
\hline Ts & \multicolumn{2}{c}{ LV Dyssynchrony } & & \multicolumn{2}{c}{ No LV Dyssynchrony } \\
\cline { 2 - 3 } & $\mathrm{n}$ & $\%$ & $\mathrm{n}$ & $\%$ \\
\hline TS-4 & 13 & 41.9 & 18 & 59.1 \\
Ts-6 & 14 & 45.2 & 17 & 54.8 \\
Ts-SD-6 & 14 & 45.2 & 17 & 54.8 \\
Ts-12 & 15 & 48.3 & 16 & 51.7 \\
Ts-SD-12 & 17 & 54.8 & 14 & 45.2 \\
\hline
\end{tabular}
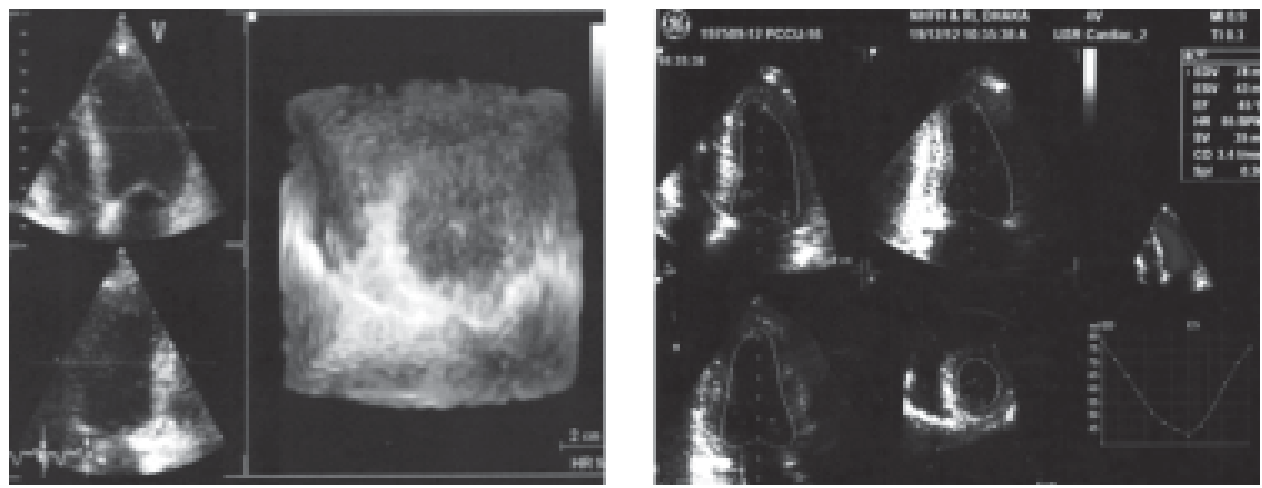

Fig.-1: RT3DE: A. apical full volume 3D data, B. reconstructed 3D model with LVEDV, LVESV and LVEF (RT3DE - real time 3D echocardiography, LVEDV - LV end diastolic volume, LVESV- LV end systolic volume, LVEF - LV ejection fraction) 

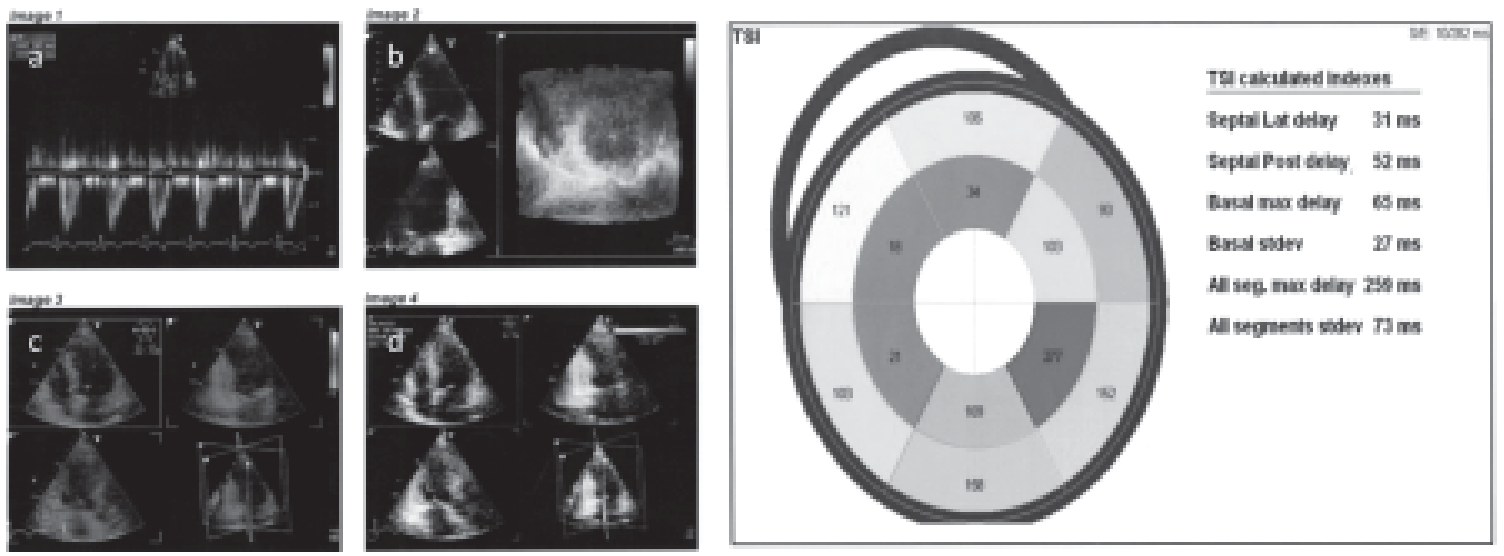

Fig.-2: RT3DE triplane TSI: a. Event timing (aortic valve opening and closure); b. full volume 3D data; c. TVI; d. TSI; e. bull's eye TSI report (TVI- tissue velocity imaging, TSI - tissue synchronization imaging)
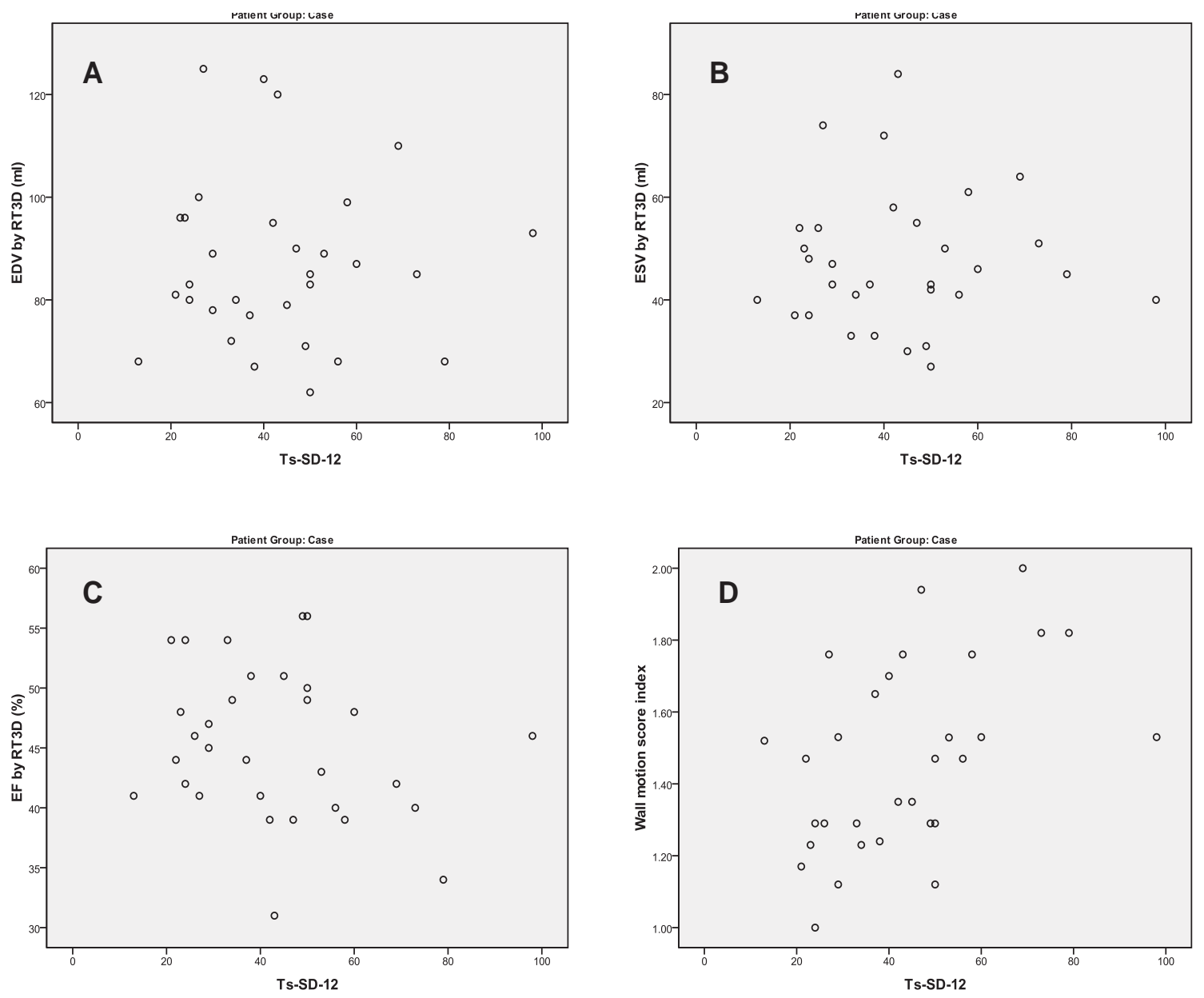

Fig.-2: Scatter plots showing correlation of TS-SD-12 with A. EDV, B. ESV, C. EF, D. WMSI (TS-SD-12 - time to peak systolic velocity in ejection phase, EDV - end diastolic volume, ESV - end systolic volume, EF - ejection fraction, WMSI - wall motion score index) there was significant correlation between TS-SD-12 and WMSI (Pearson correlation $-0.478, p<0.007$ ) 


\section{Discussion:}

Mean age difference was not statistically significant. Nearly similar pattern of age distribution were reported in different studies in Bangladesh by Wahab and Alam. ${ }^{18,19}$ But there was difference in mean age with different studies done in abroad; Nucifora et al $57 \pm 11$ and Ko SK et al $61 \pm 13$ years. ${ }^{20,21}$ Most probably this was due to the late onset of atherosclerotic coronary artery disease in developed countries than that of a third world country population. In Bangladesh, the various studies showed, the female patients formed a small percentage. Kabiruzzaman 4\% and Selim 11.5\% female patients in their respective studies. ${ }^{22,23}$ Wahab and Alam showed that smoking was the commonest risk factor in their study population. ${ }^{18,19}$ Smoking, hypertension and family history of CAD were the commonest risk factors in the study done by Nuciforaet al. ${ }^{20}$

Previously in a study by Zhang et al for the assessment of LV dyssynchrony by 2D TSI, all the patients were treated with thrombolysis. ${ }^{2}$ In their study $24(53 \%)$ patients had anterior AMI and 21(47\%) had inferior AMI. In another study by Mollema et al they recruited patients with AMI who underwent primary $\mathrm{PCl}^{12}$ Delgado et al in their study by RT3D echocardiography included patients with AMI after primary $\mathrm{PCl}^{24}$ In this study patients treated either with thrombolysis or primary $\mathrm{PCl}$ were included.

The mean ejection fraction by RT3D echo was $45 \pm 6 \%$ in patients with acute STEMI, EDV $87 \pm 16 \mathrm{ml}$, ESV $47 \pm 13 \mathrm{ml}$ and WMSI 1.5 \pm 0.25 . Zhang at el in their study found that Patients with acute MI had reduced LV systolic function, dilated LV end-systolic and end-diastolic dimensions and greater LV mass when compared with controls. ${ }^{2}$ Findings of the present study is consistent with the findings of Delgado et al by RT3DE in patients with AMI, where mean ejection fraction was $44 \pm 7 \%$, mean end diastolic volume was $108 \pm 23 \mathrm{ml}$ and end systolic volume was $60 \pm 15$ $\mathrm{ml} .{ }^{24}$ Mollema et al in their study showed baseline WMSI in acute myocardial infarction group was $1.5 \pm 0.23$, which is consistent with this study. ${ }^{25}$

Zhang et al in their study by 2D TSI echocardiography in AMI patients all Ts values were significantly prolonged than the normal healthy controls. ${ }^{2}$ They had used Ts-SD12 segment delays to identify dyssynchrony and the mean Ts-SD in AMI patients was $42.2 \pm 13.7 \mathrm{~ms}$ and in control group it was $18.0 \pm 7.0 \mathrm{~ms}$. In anterior $A M I$ it was $46.8 \pm 13.9$ $\mathrm{ms}$ and in inferior $\mathrm{AMI} 34.6 \pm 8.5 \mathrm{~ms}$. So these results were similar in the present study although the mean TS$\mathrm{SD}$ in control group was higher but within reference level. Antoni $\mathrm{ML}$ et al in their study by speckle-tracking mean difference in activation time was $61 \pm 79 \mathrm{~ms}$ and $14 \%$ patients with STEMI showed significant dyssynchrony. 26

In this study $54.8 \%$ acute STEMI patients had LV dyssynchrony identified by Ts-SD-12. Zhang et al Ts-SD of the MI group was significantly higher than the normal controls, and the prevalence of systolic asynchrony in the Ml group was $69.8 \% .^{2} \mathrm{Yu} \mathrm{CM}$ found the standard deviation of Ts of 12 LV segments was the most powerful predictor of remodeling of LV. ${ }^{1}$ Montazeri et al in their study found Ts-Sd-12 and Ts-SD-6 were more prevalent in patients with wide QRS duration then other predictors of dyssynchrony. ${ }^{27}$ Turan B et al in their study using Ts- 6 maximum delay as marker of dyssynchrony found in $23 \%$ of STEMI patients had dyssynchrony. ${ }^{6}$ Delgado et al in their study by RT3D echocardiography used SDI (systolic dyssynchrony index) as marker of dyssynchrony and SDI was higher in $45 \%$ of patients with AMI. ${ }^{24}$

There was significant correlation between Ts-SD-12 and WMSI (Pearson correlation -.478, p (2 tailed) - .007 but correlation with EDV, ESV and LVEF was not significant although both these values were significantly higher in patients with AMI. Mollemaet al in their study had similar correlation with WMSI early after AMI but in their study EDV and ESV was significantly correlated with dyssynchrony and these findings were termed as a predictor of severe LV dyssynchrony and late LV remodeling. ${ }^{12}$ In line of these findings LV dyssynchrony in acute STEMI was significantly associated with LV functions specially WMSI and related with changes in LV volumes.

\section{Limitations:}

Although the results of this study support the hypothesis, there were some limiting factors which might influence the results:

- $\quad$ Sample size was small.

- Disparity of gender.

- Difference in time of echocardiography after AMI

- Inter and intra observer variability was not done.

\section{Conclusion:}

The present study illustrates that LV systolic dyssynchrony is a relatively common feature in patients with acute STEMI. This occurs early in STEMI even in the absence of wide QRS complexes. In addition, patients with anterior myocardial infarction have more severe LV systolic dyssynchrony than those with inferior myocardial infarction.

\section{Recommendation:}

LV dyssynchrony soon after AMI may cause severe detrimental impact on LV performance and it may potentiate to the vicious cycle of progressive LV dysfunction. Larger studies including clinical end points and long term follow-up and angiographic correlations are required to examine the significance of LV dyssynchrony in acute STEMI. 


\section{References:}

1. $\mathrm{Yu}$ CM, Zhang Q, Fung JH. Assessment of Dyssynchrony and Its Application: Myocardial Imaging: Tissue Doppler and Speckle Tracking; Thomas H. Marwick; Published Online, Copyright (C) 2007 Blackwell Publishing Ltd. 2008; ch9; 102-127.

2. Zhang $\mathrm{Y}$, Chan AKY, Yu CM, et al. Left Ventricular Systolic Asynchrony After Acute Myocardial Infarction in Patients with Narrow QRS Complexes. American Heart Journal.2005; 149:497-503.

3. Yu CM, Fung WH, Lin H, Zhang Q, Sanderson JE, Lau CP. Predictors of left ventricular reverse remodeling after cardiac resynchronization therapy for heart failure secondary to idiopathic dilated or ischemic cardiomyopathy. American Journal of Cardiology. 2003; 91:684-688.

4. Pfeffer MA and Braunwald E. Ventricular remodeling after myocardial infarction. Experimental observations and clinical implications. Circulation.1990; 81:1161-1172.

5. Bolognese L, Neskovic AN, Parodi G, et al. Left ventricular remodeling after primary coronary angioplasty: patterns of left ventricular dilation and long term prognostic implications. Circulation. 2002; 106:2351-2357.

6. Turan B, Yilmaz F, Karaahmet T, Tigen K, Mutlu B, Basaran Y. Role of left ventricular dyssynchrony in predicting remodelling after ST elevation myocardial infarction. Echocardiography. 2012; 29:165-172.

7. Galderisi M, Cattaneo F, Mondillo S. Doppler echocardiography and myocardial dyssynchrony: a practical update of old and new ultrasound technologies; Cardiovascular ultrasound. 2007; 5:28-42.

8. Boissiere J, Gautier M, Machet MC, Hanton G, Bonnet $\mathrm{P}$, Eder V. Doppler tissue imaging in assessment of pulmonary hypertension-induced right ventricle dysfunction. American Journal of Physiology-Heart and Circulatory Physiology. 2005; 289: 2450-2455.

9. Bader H, Garrigue S, Lafitte S, et al. Intra-left ventricular electromechanical asynchrony A new independent predictor of severe cardiac events in heart failure patients. Journal of the American College of Cardiology. 2004; 43(2):248-256.
10. Nico R Van de Veire, Gabe B Bleeker, Johan de Sutter, Roelandt JRTC. Technological advances in tissue Doppler echocardiography, Heart. 2008; 94:1065-74.

11. Mollema SA, Nucifora G, Bax JJ. Prognostic value of echocardiography after acute myocardial infarction. Heart. 2009; 95:1732-45.

12. Mollema SA, Liem S, Suffoletto S, et al. Left Ventricular Dyssynchrony Acutely After Myocardial Infarction Predicts Left Ventricular Remodeling. Journal of the American College of Cardiology. 2007; 50:1532-1540.

13. Nanda N C, Kisslo J, Lang R, et al. Examination protocol for three-dimensional echocardiography. Echocardiography. 2004; 21(8):763-768.

14. Marsan N A, Tops L F, Nihoyannopoulos P, Holman E R, Bax J J. Real-time three dimensional echocardiography: current and future clinical applications. Heart. 2009; 95:1881-1890.

15. Badano, L.P., Agricola, E., Perez de Isla, L., Gianfagna, P. and Zamorano, J.L. Evaluation of the tricuspid valve morphology and function by transthoracic real-time three-dimensional echocardiography. European Journal of Echocardiography. 2009;10: 477-484.

16. Breithardt O, Floer S, Golldschmidt HJ, Heimdl A, Phillip S. Tissue Synchronization Imaging (TSI) in Clinical Practice. GE whitepaper, GE Healthcare. 2006.

17. Powell BD, Espinosa RE, Yu CM, Oh JK. Tissue Doppler imaging, Strain Imaging and dyssynchrony Assessment. In: Jae k Oh, James B Seward, A Jamil Tajik, eds. The Echo Manual. $3^{\text {rd }}$ ed. Lippincott, Williams \& Wilkins. 2006; 80-98.

18. Wahab S.M.A., Islam AEMM, Haque MM, et al. Comparative study between 12 and 15 lead electro cardiogram for evaluation of acute posterior myocardial infarction. Cardiovascular Journal. 2012; 4(2): 153-163.

19. Alam MS, Ullah M, Ulabbi SU, et al. Prediction of the site of coronary artery lesion in acute inferior myocardial infarction with right sided precordial lead (V4r). Cardiovascular Journal. 2011; 4(1): 46-52.

20. Nucifora G, Bertini M, Marsan NA, et al. Impact of left ventricular dyssynchrony early on left ventricular function after first acute myocardial infarction. American Journal of Cardiology. 2010; 105:306-11. 
21. Ko JS, Jeong MH, Lee MG, et al. Left ventricular dyssynchrony after acute myocardial infarction is a powerful indicator of left ventricular remodeling. Korean Circulation Journal. 2009; 39(6):236-242.

22. Kabiruzzaman M., Ali M.A., Islam, M.N. Coronary Angiographic Characteristics of patient with first Myocardial Infarction Admitted in a Tertiary Care Cardiac Hospital in Bangladesh. Cardiovascular Journal. 2010; 2(2): 204-11.

23. Mahmod MS, Malik F, Rahman MA, Sarkar MRI, Masum MS. association of duration of diabetes mellitus with the severity of coronary artery disease in NSTEMI diabetic patients. Bangladesh heart journal. 2014; 29:12-17.

24. Delgado V, Siages M, Vidal B, et al. Assessment of left ventricular dyssynchrony by real time three- dimensional echocardiography. Revista Española de Cardiología (English Version). 2008; 61(8): 825-34.

25. Mollema SA, Nucifora G, Bax JJ. Prognostic value of echocardiography after acute myocardial infarction. Heart. 2009; 95:1732-45.

26. Antoni M L, Boden H, Hoogslag G E, et al. Prevalence of Dyssynchrony and Relation with Long -Term Outcome in Patients After Acute Myocardial Infraction. American Journal of Cardiology. 2011; 108: $1689-1696$.

27. Montazari M, Rezvanfard M, Kazemisaeid A, et al. Assessment of left ventricular dyssynchrony in heart failure patients regarding underlying etiology and QRS duration. The Journal of Tehran University Heart Center. 2011; 6(4):192-201. 